\title{
La ética del periodista en la infoesfera digital
}

\author{
Juan Carlos Suárez Villegas \\ (Universidad de Sevilla)
}

Recibido: $20 / 1 / 2013$

Aceptado: 28/5/2013

\begin{abstract}
Resumen: En este artículo se plantean los nuevos retos a los que se enfrenta la actividad informativa en la era de internet, caracterizada por la horizontalidad y transversalidad de los modelos comunicativos entre medios y ciudadanos. Pensar sobre conceptos como la responsabilidad social, la veracidad y la elaboración de agendas informativas en la creación de la opinión pública se antoja absolutamente fundamental para delimitar la función del periodista en el entorno digital.
\end{abstract}

Palabras clave: Periodismo digital / responsabilidad / internet / ciudadanía / información

\section{Journalism ethics on digital infosphere}

ABSTRACT: This article presents new challenges facing the transmition of information in the internet era, characterized by the horizontal and transversal communication models between media and citizens. Concepts such as social responsibility, truthfulness and the development of news agendas leading public opinion are fondamental in order to understand the new roles of journalists in the digital environments.

Keywords: Digital journalism / responsibility / internet / citizenship / information

1 Esta investigación ha sido realizada dentro del proyecto I+D+I del Ministerio de Ciencia e Innovación del Gobierno de España, titulado «Los desafíos éticos del periodismo digital. Análisis comparativo entre cinco países europeos», con referencia CSO2011-26620. 


\section{Introducción}

La emergencia de nuevas formas periodísticas digitales, mediada y favorecida por el desarrollo acelerado de las aplicaciones informáticas conocidas con el nombre de Web 2.0 es, sin lugar a dudas, uno de los signos más visibles del Zeitgeist de la sociedad de la información. En un universo informativo en el que cualquier individuo que conoce y maneja las tecnologías de autopublicación, redes sociales, microblogging, etcétera, puede convertirse en productor de información, los medios de comunicación oficiales y privados desarrollan nuevas estrategias y prácticas informativas para diferenciarse de los «amateurs» (blogueros y sitios de periodismo "ciudadano») que se esfuerzan por ganar visibilidad y seguidores en el vasto ecosistema de la infoesfera (Casasús 2001, Díaz 1996a y 1996b). Sin embargo, es preciso constatar que el doble proceso de adopción/ adaptación implicado por las nuevas tecnologías de la información y la comunicación digital trae consigo desafíos éticos en términos de la identidad profesional de los periodistas, los valores sociales y morales que subyacen a sus prácticas digitales y las normas de excelencia que el público exige para garantizarle al periodismo en línea su pertinencia y necesidad en el seno de una sociedad democrática (Singer y Friend 2007; Kovach y Rosenstiel 2007). En este sentido, puede observarse que las definiciones mismas de «periodismo» $\mathrm{y}$ «periodista» han sufrido profundas reconfiguraciones, en parte como resultado de la tecnologización creciente de la recolección, procesamiento y difusión de la información, pero también como consecuencia del cambio gradual del papel del público, que otrora era percibido como un consumidor «pasivo» de los medios de comunicación y la información (Allan 2006 y Gillmor 2006).

En el panorama de la infoesfera digital contemporánea cohabitan dos tipos de medios informativos cuyos orígenes ilustran dos tendencias sociotecnológicas (Bruns 2008). Por un lado, podemos observar los medios en línea «nativos» o pure players, es decir, medios informativos creados originalmente como plataformas animadas por un espíritu digital puro que comporta sus propios valores y normas: el trabajo colaborativo, la relación dialógica, interactiva y reticular entre los productores de información y el público; la transparencia en cuanto a las políticas de selección y filtraje de la información; y la claridad respecto de las fuentes que financian el medio. Por otro lado, encontramos los medios en línea «importados» $\mathrm{u}$ online mainstream media; es decir, las versiones web de los medios de comunicación tradicionales que han emigrado hacia nuevas plataformas en línea intentando, al mismo tiempo y con mayor o menor éxito, adaptar sus políticas verticales de producción y acceso crítico del público a la información: toma de decisiones jerárquicas en las salas de redacción 
web; políticas editoriales de gatekeeping verticales, reacciones del público moderadas subjetivamente por un periodista o un webmaster en los foros de discusión de los artículos, etcétera (Singer y Friend 2007, capítulo 2).

Sin embargo, es necesario notar que estas dos tendencias sociotecnológicas de la información digital funcionan como los extremos de un espectro en el que diferentes variaciones ocurren de acuerdo con las intenciones y pretensiones de un medio en línea particular (Fenton 2010). Por ejemplo, para ciertos medios «importados» la interacción con el público constituye un valor importante en términos de la construcción y mantenimiento de su credibilidad, mientras que para otros la credibilidad es simplemente una cuestión de producción de reportajes objetivos, imparciales, veraces, con calidad y pertinencia para los ciudadanos (Tunney y Monaghan 2010).

Por otro lado, como ha señalado el profesor Díaz Noci (1996a y 1996b), en función de la primera característica, el aspecto textual, aunque predominante aún en la mayoría de los servicios informativos, entre otras razones por facilidad técnica de transmisión, ha dado paso a la integración en un único discurso de elementos audiovisuales, de manera que se está construyendo una retórica que el francés Jean Cloutier ha denominado «audioescritovisual»(Cloutier 1994: 43). A este respecto, Díaz Noci (1996b) indica que con la interactividad se aspira a supe- rar las limitaciones del sentido unidireccional de la comunicación de los medios tradicionales, en los que existe un único emisor y un único receptor genérico compuesto de diversos perfiles de consumidores, para dar paso a un acceso a la información diferenciado de acuerdo con intereses singularizados y producir los denominados «nichos de audiencia». De este modo, a través de internet todos los grupos, por pequeños que fuesen, podrían encontrar vías para satisfacer sus intereses informativos, cuestión que sería prácticamente imposible a través de los medios tradicionales.

En este espacio de interactividad, en la que la disponibilidad de comunicar y de acceder a la comunicación puede generar ciertas patologías derivadas del deseo de superar la invisibilidad de una realidad en la que los sujetos se hacen cada vez más líquidos y más invisibles. Richard Mason, en su conocido artículo titulado «Four ethical issues of the information age» (1986), señalaba ya entonces cuatro temas éticos cruciales en la colisión entre el potencial de las nuevas tecnologías de la información y los derechos que había que preservar frente a sus posibles abusos: la intimidad (privacy), exactitud (accuracy), propiedad intelectual (property) y accesibilidad (accessibility) (Barroso 1997).

Los desafíos éticos que surgen con el periodismo digital y otros formatos como los blogs y el periodismo ciudadano, conciernen esencialmente a 
cuatro dimensiones de lo que puede llamarse «práctica periodística en línea», a saber, la producción, difusión, recepción y evaluación de la información. La pertinencia filosófica y social de este proyecto estriba, pues, en la necesidad académica y democrática de identificar, comprender, analizar normativamente y formular políticas adecuadas para el tratamiento de los conflictos éticos generados por la utilización de la tecnología en el periodismo digital (Meyers 2010) y profundizar, desde un punto de vista ético, las premisas establecidas por otros trabajos de investigación focalizados en aspectos sociopolíticos del periodismo digital a nivel europeo (Carpentier et al., 2008).

Manuel Castells destaca en relación con la credibilidad de los medios en internet, cómo en el caso de los periódicos en papel, el prestigio que ya tienen se convierte en una ventaja en la red:

Internet no está afectando a los periódicos de información general porque, en un mundo de información ilimitada, la credibilidad es un ingrediente esencial para la gente que busca dicha información. Por lo tanto, los periódicos con un prestigio establecido deben ser accesibles on line, con el objeto de estar siempre disponibles para sus lectores y mantenerlos siempre bajo su halo de autoridad [...] (Castells 2001: 225).

$\mathrm{Y}$ atendiendo a estas ideas previas nos planteamos: ¿cuál es el papel del periodista en esta sociedad digital? Es precisamente la ética la cuestión clave, el cumplir con unas normas deontológicas lo que diferencia el contenido emitido por los medios, por un periodista, del que difunde cualquier otra persona, grupo de personas o institución. Suele afirmarse que el papel del periodista en esta nueva sociedad digital es el de convertirse en un filtro de los contenidos de calidad, en un intermediario entre los ciudadanos y la ingente cantidad de información - de mejor o peor calidad-, que se difunde a través de la red.

Por otra parte, hemos de mencionar que el periodista dispone en el medio digital, gracias a su carácter multimedia, de muchos más recursos que el resto de medios para ofrecer la información: texto, imágenes, animaciones, vídeos, infografías, etcétera. Y que también existe la posibilidad de interactividad, de forma que puede establecer un diálogo con sus lectores. Más bien - como puede verse en el ejemplo de los comentarios a las noticias- el diálogo sería de los lectores con el medio y entre ellos mismos, pero no con los periodistas, que no suelen intervenir, precisamente porque si están difundiendo información, una opinión suya respecto a cualquier comentario no tendría mucho sentido. En cambio, sí es más probable que se dé este diálogo entre autor y lector en el caso de un artículo de opinión.

Por último, el periodista en el medio digital «se libera» o «puede libe- 
rarse» del yugo de la empresa periodística y publicar cualquier tipo de información sin estar sometido a los criterios de selección del medio. Lo cual también supone una ventaja más de internet respecto a otros medios. En resumen, en internet el periodista puede hacer periodismo de manera «independiente».

En el debate en torno al concepto del periodismo en el medio digital: ¿qué se entiende hoy día por periodismo en el medio digital y puede considerarse periodismo el llamado «periodismo ciudadano» surgido en el contexto de la Web 2.0? Todos los ciudadanos tenemos derecho a expresarnos, a difundir nuestras ideas y opiniones, a dar nuestra propia versión de los hechos, ajena, tal vez, a la que difunden los medios. Pero la información que cualquier ciudadano difunde, ¿puede ser considerada periodismo?, ¿qué criterio deberíamos establecer para delimitar qué es periodismo realmente? Si consideramos que el cumplimiento de su deontología profesional es el requisito fundamental para un periodista, ¿está haciendo periodismo un ciudadano que difunde una noticia si cumple esas normas deontológicas?

El defensor del periodismo ciudadano, Juan Valera, señala con bastante acierto que publicar no es igual que informar. El periodismo, la investigación, la elaboración y la difusión de información, necesita tiempo, recursos y una actitud ética y profesional. Los blogueros no tienen por qué tenerla (Varela 2005: 117).
Una vez tenidas en cuenta todas estas ideas y analizadas todas estas cuestiones podríamos por fin pasar a hablar sobre la ética en el periodismo digital. Partiendo de la base de que el periodista digital está sujeto a las mismas normas deontológicas que cualquier otro medio. Aquí nos surgiría la siguiente pregunta: ¿qué determina la ética en el periodismo digital, el periodista, el propio medio o las características del canal a través del que se difunde la información?

Para responder a esta cuestión, resulta imprescindible tener el cambio gradual de paradigma en el que los modelos y valores tradicionales del periodismo se enfrentan a los imperativos provenientes de cambios tecnológicos vertiginosos, nuevos modelos económicos de producción/difusión de la información y adaptaciones de los modelos culturales de consumo de la información en términos de rapidez, eficiencia, interactividad y personalización. En este sentido, la primacía del reportaje instantáneo, la omnipresencia de las noticias, el acceso global a la información, la interacción reticular del público con los medios y la constante actualización de contenidos son algunas de las características de este nuevo paradigma en el que se desarrolla el periodismo digital.

Como resultado de esta evolución sociotécnica, el periodismo digital se ha convertido igualmente en producto multimedia. Investigaciones sobre la convergencia tecnológica de los medios de comunicación (Jenkins 2006) 
han puesto de manifiesto las diferentes maneras en que la información en la era digital se diversifica y converge, semántica y narrativamente, a través de diferentes soportes tecnológicos. De esta manera, el periodismo digital representa hoy en día una forma de producción de la información que se adapta a las demandas y preferencias del público lector: contenidos personalizables según el tipo de suscripción, seguimiento de flujos RSS, venta de aplicaciones diseñadas para teléfonos celulares y tabletas táctiles, etcétera. Las consecuencias de este fenómeno de convergencia para el periodismo digital son evidentes. Mientras que los periodistas y editores se esfuerzan por adaptar los valores de la práctica periodística al nuevo entorno digital, los propietarios de los medios de comunicación digitales propugnan estrategias de marketing agresivas para conquistar nuevos públicos garantizando un margen de acción cada vez mayor a las empresas publicitarias que quieren pautar con ellos (Sanders 2003). Al mismo tiempo, la incorporación de nuevas técnicas de análisis de bases de datos (data journalism), el trabajo colaborativo en redes locales e internacionales y la emergencia de modelos de subcontratación voluntaria (crowdsourcing), en las que el ciudadano colabora con los periodistas realizando tareas de identificación y recolección de informaciones de interés público, exigen a los periodistas digitales la posesión de competencias informáticas y administrativas que van más allá de la simple capacidad necesaria para producir un reportaje de calidad. En este contexto, resulta necesario examinar algunas cuestiones centrales de la deontología periodística en el entorno digital (Knowlton y Reader 2009, Keeble 2005).

\section{Presentación de algunos problemas éticos del periodismo digital}

El cambio de paradigma introducido por las nuevas tecnologías de la información y la comunicación en el periodismo trae consigo implicaciones éticas tanto para la práctica periodística misma como para la información publicada en línea. Estas implicaciones provienen de diversas fuentes, como las restricciones/oportunidades de las aplicaciones informáticas utilizadas, la estructura competitiva del mercado de la información digital, las políticas nacionales e internacionales que regulan los medios digitales, la evolución de los modos culturales de consumo de información, el ritmo acelerado de la producción de información y las demandas de un público cada vez más participativo y crítico de los medios, entre otros. Cada una de estas fuentes contribuye en diversos grados a que los periodistas y editores que trabajan en entornos digitales revisen constantemente las normas de excelencia y los valores que subyacen a su profesión. De manera breve, vamos a relacionar aquí algunos de los dilemas éticos a los que se enfrenta el periodismo digital (figura 1): 
Figura 1

Dimensiones de desafío y posible conflicto ético en el periodismo digital

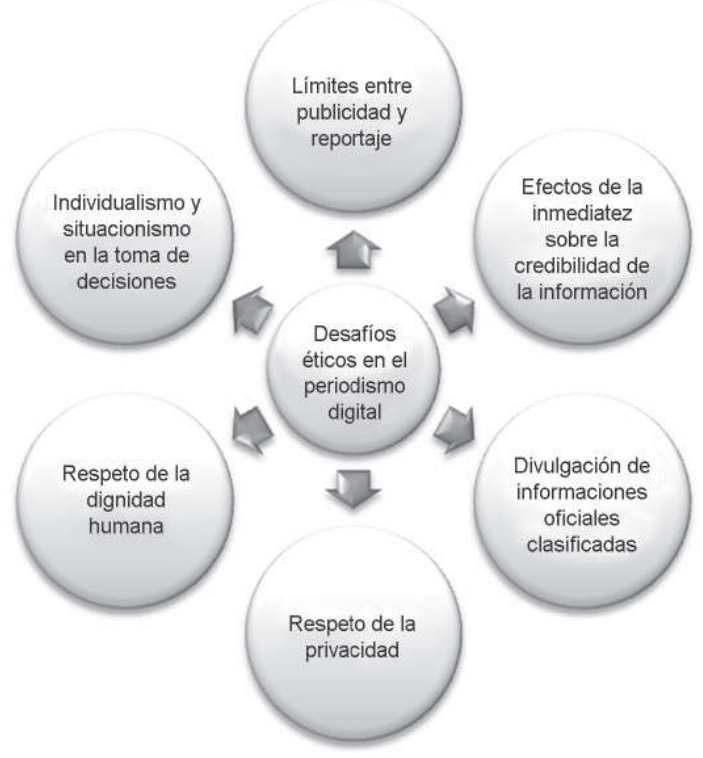

1. Límites entre publicidad y reportaje.Esta temática concierne a la necesidad de distinguir claramente entre contenido periodístico y contenido publicitario. Las situaciones conflictivas que pueden tener lugar aquí incluyen decisiones editoriales que llevan a una sobrecarga de banners publicitarios en las páginas de inicio de los sitios periodísticos digitales; implicaciones de la utilización de aplicaciones informáticas destinadas a la publicidad contextual dentro de un artículo; negociación de pautas con los patrocinadores publicitarios y sus efectos sobre la selección de temas informativos; y colaboración entre medios digitales y organizaciones privadas para la promoción de bienes en línea.
2. Efectos de la inmediatez sobre la credibilidad de la información.- En este campo se concentran los conflictos entre los valores de precisión, fiabilidad y veracidad de testimonios e informaciones recogidos digitalmente y el imperativo de publicación inmediata; la inserción de hipervínculos en los artículos hacia sitios insuficientemente verificados; y la oposición entre corrección pública y corrección en secreto (actualización) de posibles errores o informaciones imprecisas en un reportaje (Rosas 2012, Lee 2010, Ziomek 2005).

3. Divulgación de informaciones oficiales clasificadas.- Trata de la toma de decisiones editoriales conducentes a la publicación de informes clasi- 
ficados en aras del interés público (por ejemplo, Wikileaks); la difusión pública de entrevistas acordadas «en off»; y la utilización de cámaras escondidas para revelar informaciones oficiales y privadas comprometedoras (Lasica 2004).

4. Respeto de la privacidad.- En esta sección se agrupan las situaciones conflictivas respecto de la divulgación de datos personales obtenidos vía testimonios, vigilancia ocasional o sistemática de informaciones en los perfiles de las redes sociales; audios o videos grabados y difundidos en línea sin el consentimiento previo de las personas involucradas; moderación de discusiones racistas y discriminatorias en los comentarios a las noticias en línea; y la instalación automática de cookies en los ordenadores de los suscriptores a medios digitales y su ulterior transmisión a sociedades comerciales sin consentimiento previo (LaMay 2003).

5. Respeto de la dignidad humana.- Esta temática comprende tópicos como la profusión repetitiva y sensacionalista de imágenes, audios $\mathrm{y}$ videos de catástrofes naturales, crímenes, procesos judiciales, etcétera; o la revelación de datos personales de presuntos criminales o terroristas antes de su respectiva inculpación oficial (Ploug 2009).

6. Individualismo y situacionismo en la toma de decisiones.- Se refiere a situaciones en las que la perspectiva personal y contextual del periodista entra en conflicto con las normas periodísticas de protección de la privacidad o la dignidad humana.

\section{Conclusiones}

Estos dilemas éticos del periodismo de siempre se agudizan en buena medida en el ámbito digital, por lo que exigen de los profesionales de la información extremar su conducta ética, a fin de hacer del periodismo un referente de credibilidad informativa para la ciudadanía y distinguirse así de otras formas espurias de comunicación a la que invita la interactividad entre ciudadanos privados. En este sentido, la calidad se convierte en un concepto crítico de la ética en el periodismo digital, capaz de hacer la información más interactiva y extensa en sus contenidos, pero vigilando para que estas posibilidades no se conviertan en una pendiente resbaladiza hacia prácticas que puedan lesionar tanto los derechos de las personas aludidas en la noticia, como el derecho a la ciudadanía a una información diligente y formativa, basada en el respeto a la verdad y el pluralismo informativo. Frente a una tendencia sociológica de usuarios que tienden a concederle credibilidad a lo que encuentra en el ciberespacio, el periodismo debería actuar con criterios deontológicos claros para revalidar la confianza de la ciudadanía. En particular, ha de prestar especial atención a los riesgos de convertir la 
pantalla en un escenario de exhibición de la intimidad o de los exabruptos más desafortunados con los que algunos buscan llamar la atención de los medios. El rigor informativo requiere prácticas como la comprobación de fuentes y pluralidad de versiones de los hechos, por lo que el periodista debe abstenerse de publicar hechos de los que no conozca su origen o hacerlo con una precipitación innecesaria que desacredite la confianza en su función pública. Por eso, los medios de comunicación han de actuar de manera diligente para lograr una información contrastada y de interés público, evitando actuar como meros repetidores de noticias, cuestión sobradamente resuelta hoy día por las redes sociales.

La ética constituye la seña de identidad del periodismo como una profesión dedicada a atender el derecho de la ciudadanía a la información. Por eso, el periodista frente a nuevos emisores emergentes que interactúan en el ámbito digital ha de mantener su compromiso con una serie de deberes básicos que caracterizan la labor del periodista profesional, como son la comprobación de fuentes, frente a la precipitación informativa; atender a la pluralidad de voces, frente a la difusión de aquellas más influyentes; respeto a los derechos de las personas, frente a actitudes desaprensivas de quienes atentan contra la intimidad, la imagen y el honor de los individuos para producir informaciones más sensacionalistas.

\section{Bibliografía}

Allan, S. (2006). Online News. Journalism and the Internet. Berkshire: Open University Press.

Barroso, P. (noviembre de 1997). "Cuatro principios de ética en Internet». ZER 3. Revista de estudios de comunicación. Universidad del País Vasco, Servicio Editorial.

Bruns, Axel (2008). Gatewatching: Collaborative online news production. Nueva York: Peter Lang.

Carpentier, N. et al. (2008). Democracy, journalism and technology: New developments in an enlarged Europe. Tartu, Estonia: Tartu University Press; K.

Casasús, J. M. (2001). «Perspectiva ética del periodismo electrónico». Estudios del mensaje periodístico 7. $<$ http://www.ucm.es/info/emp/ Numer_07/7-3-Pone/7-3-03.htm>. [Consulta: 4 de febrero del 2012].

Castells, M. (2001). La galaxia internet: Reflexiones sobre internet, empresa y sociedad. Madrid: Areté.

Díaz Noci, Javier (1996a). «Desarrollo del periodismo electrónico», conferencia pronunciada en las IV Jornadas sobre Comunicación y Nuevas Tecnologías, Universidad del País Vasco. <http://www. pd.lp.ehu.es/Website/Memoria/ Docentes/Díaz\%20Noci/Textos/ Conferencias/TRAINTEC.html>. [Consulta: 5 de agosto del 2011].

Díaz Noci, J. (1996b). «Conceptos en torno al periodismo electró- 
nico multimedia interactivo». Conferencia pronunciada en el curso de verano sobre «El periodismo electrónico en la era del ciberespacio». San Sebastián: Universidad del País Vasco, 15 de julio. <http:// www.pd.lp.ehu.es/Website/ Memoria/Docentes/Díaz\%20Noci/ Textos/Conferencias/donosti.html>. [Consulta: 6 de agosto del 2011].

Fenton, N. (ed.) (2010). New media, old news. Journalism and democracy in the digital age. Londres: Sage.

Gillmor, Dan (2006). We the media: Grassroots journalism by the people, for the people. Sebastopol: CA: O'Reilly. $<$ http://www.pd.lp.ehu.es/Website/ Memoria/Docentes/Díaz\%20Noci/ Textos/Conferencias/TRAINTEC. html>. [Consulta: 21 de noviembre del 2009].

Jenkins, Henry (2006). Convergence culture: Where old and new media collide. Nueva York: New York University Press.

Keeble, R. (2005). Communication ethics today. Leicester: Troubadour Publishing.

Knowlton, S. y B. Reader. (eds.) (2009). Moral reasoning for journalists. Westport, CT: Praeger Publishers.

Kovach, B. y T. Rosentiel (2007). The elements of journalism. What newspeople should know and the public should expect. Nueva York: Three Rivers Press.
LaMay, C. L. (2003). Journalism and the debate over privacy. Mahwah, NJ: Lawrence Erlbaum.

Lasica, J. D. (2004). «Transparency begets trust in the ever-expanding blogosphere. Online Journalism Review. <http://www.ojr.org/ojr/ technology/1092267863.php>. [Consulta: 9 de mayo del 2011].

Lee, T.-T. (2010). «Why they don't trust the media? An examination of factors predicting trust». American Behavioral Scientist 54(1), pp. 8-21.

Meyers, C. (ed.) (2010). Journalism ethics: A philosophical approach. Nueva York: Oxford University Press.

Ploug, T. (2009). Ethics in cyberspace. How cyberspace may influence interpersonal communication. Nueva York: Springer.

Rosas, O. (2012). Trust in online news. Arc Project. University of Namur.

Sanders, K. (2003). Ethics and journalism. Londres: Sage.

Singer, B. y C. Friend (2007). Online journalism ethics: Traditions and transitions. Nueva York: M. E. Sharpe.

Singer, J. B. (2006). Partnership and public service: Normative issues for journalists in converged newsrooms. Journal of Mass Media Ethics 21(1), pp. 30-53.

Tunney, S. y G. Monaghan (eds.) (2010). Web journalism: A new form of citizenship? Brighton: Sussex Academic Press. 
Varela, Juan (2005). «Periodismo participativo: el Periodismo 3.0», en Rojas, Octavio I.; Alonso, Julio; Antúnez, José Luis; Orihuela, José Luis y Juan Varela. Blogs: La conversación en Internet que está revolucionando medios, empresas y ciudadanos. Madrid: ESIC.
Ziomek, J. (2005). Journalism, transparency and the public trust. A report of the Eight Annual Aspen Institute Conference on Journalism and Society. Washington, DC: The Aspen Institute. 